\title{
Conceptualizing sexual and gender-based violence in European asylum reception centers
}

\author{
Charlotte Oliveira $^{1 *} \mathbb{D}$, Maria do Rosário Oliveira Martins ${ }^{1}$, Sónia Dias ${ }^{1,2}$ and Ines Keygnaert ${ }^{3}$
}

\begin{abstract}
Background: Sexual and gender based violence (SGBV) is a major public health problem and a violation of human rights. Refugees, asylum seekers and migrants are exposed to a constant risk for both victimization and perpetration. Yet, in the context of European asylum reception centers (EARF) professionals are also considered to be at risk. Our study explores the conceptualization of SGBV that residents and professionals have in this specific context. Further, we intent to identify key socio-demographic characteristics that are associated with SGBV conceptualization for both groups.
\end{abstract}

Methods: We developed a cross-sectional study using the Senperforto project database. Semi-structured interviews were conducted with residents $(n=398)$ and professionals $(n=202)$ at EARF. A principal component analysis (PCA) was conducted to variables related with knowledge on SGBV. Chi-square test and Fisher's exact test were applied to understand if significant statistical association exists with socio-demographic characteristics (significant level 0.5\%).

Results: The majority of residents were male (64.6\%), aged from 19 to 29 years (41.4\%) and single (66.8\%); for professionals the majority were women (56.2\%), aged from 30 to 39 years (42.3\%) and married (56.8\%). PCA for residents resulted in 14 dimensions of SGBV representing $83.56 \%$ of the total variance of the data, while for professionals it resulted in 17 dimensions that represent $86.92 \%$ of the total variance of the data. For both groups differences in SGBV conceptualization were found according to host country, sex, age and marital status. Specific for residents we found differences according to the time of arrival to Europe/host country and type of accommodation, while for professionals differences were found according to legal status and education skills.

Conclusion: Residents and professionals described different conceptualization of SGBV, with specific types of SGBV not being recognized as a violent act. Primary preventive strategies in EARF should focus on reducing SGBV conceptualization discrepancies, taking into account socio-demographic characteristics.

Keywords: Sexual and gender based violence, Sexual violence, Refugees, Asylum-seekers, Migrants, Asylum reception centres, Professionals, Conceptualization, Prevention

\section{Background}

Sexual and Gender-based Violence (SGBV) is a major public health problem and a violation of human rights $[1$, 2]. SGBV encompasses gender-stereotyped acts of violence, based on unequal power relations and denying human dignity, rights and development $[1,3]$.

\footnotetext{
* Correspondence: charlotte.oliveira@ihmt.unl.pt

${ }^{1}$ Global Health and Tropical Medicine, GHTM, Instituto de Higiene e Medicina Tropical, IHMT, Universidade NOVA de Lisboa, Rua da Junqueira 100,

1349-008 Lisbon, Portugal

Full list of author information is available at the end of the article
}

Considering the global challenge of (forced) migration [4], United Nations High Commissioner for Refugees (UNHCR) defines SGBV as “(...) violence that is directed against a person on the basis of gender or sex. It includes acts that inflict physical, mental or sexual harm or suffering, threats of such acts, coercion and other deprivations of liberty (....)" [1]. SGBV comprises five categories, namely, physical, psychological, sexual, socio-economic violence and harmful cultural practices [1]. SGBV conceptualization is a matter of judgement, affected by cultural beliefs, social norms and values [5]. What is considered a violent behavior

(C) The Author(s). 2019 Open Access This article is distributed under the terms of the Creative Commons Attribution 4.0 International License (http://creativecommons.org/licenses/by/4.0/), which permits unrestricted use, distribution, and 
varies according to specific determinants such as sociocultural and historical conditions [6].

Referring to SGBV conceptualization within the context of European Union (EU) policy documents, SGBV in general, and more specifically in migrants, has been framed as violence against women $[7,8]$. Yet, literature has demonstrated that female, male and transgender refugees, asylum seekers (AS) and migrants are vulnerable to SGBV [4, 913]. In a study on SGBV among refugees, AS and undocumented migrants in European asylum reception centers (EARF) a high percentage of multiple types of SGBV was reported in all sexes [14]. A study done in Belgium and the Netherlands found a high prevalence of direct or indirect SGBV exposure among migrant: 87/223 respondents had been personally victimized since their arrival in Europe. The majority of perpetrators were male (74.0\%), and $69.3 \%$ of victims were female (male victims were 28.6\%). Also, asylum related professionals were found to be assailants in one fifth of the reported violence [13].

A socio-ecological approach is described in the literature as an understanding model for SGBV $[1,2,15]$. The model assumes SGBV as the result of a permanent and dynamic interaction between health determinants at four levels: individual, relational, community and society [1, 2 , 15]. A combination of these levels triggers the patterns of SGBV $[16,17]$. At individual level, research has shown that women and girls, especially the impoverished are more prone to victimization $[13,18]$. Recent evidence demonstrates that boys and men are also exposed to sexual violence [19]. In the context of EARF, both females and males have a tendency to be victims and/or perpetrators [14]. Furthermore, age [20], attained education and cultural beliefs appears to be important determinants when addressing SGBV [10]. At a relational level, children exposed to a violent context are more susceptible of becoming victims and/or perpetrators [21]. Further, a systematic review highlights that immigrant adolescents are exposed to high rates of violence [22]. From a community and societal perspective, studies have shown that an important determinant for sexual violence among refugees, AS and undocumented migrants is their restricted legal status [7] and the migration process itself [3].

In the context of migration, it becomes relevant to engage with affected communities [23] and to understand legal power relations triggered by society constructed knowledge, beliefs and norms that undermine refugees, AS and migrants, threatening their human rights and putting them at higher risk of SGBV [24]. Primary prevention of SGBV should focus on measures ensuring 'basic condition for sustainable and effective change' [25]. In this sense, a wide conceptualization of SGBV from an individual, relational, community and societal perspective is needed to promote a comprehensive prevention approach to violence [26].
Moreover, the intersectional nature of SGBV should be acknowledged while addressing preventive measure $[8,27]$.

Our study aims to expand the understanding of SGBV conceptualization, in a vulnerable population of refugees, AS and migrants on the one hand and in professionals working with these communities in EARF on the other. Further, we identify sociodemographic characteristics of both groups that can be associated with SGBV conceptualization.

\section{Methods \\ Study design}

A cross-sectional study was conducted using data from the Senperforto Project developed in eight European countries (Belgium, Greece, Hungary, Ireland, Malta, The Netherland, Portugal and Spain). The main objective of Senperforto was to explore what knowledge, attitude, practice (KAP), and needs of professionals and residents from EARF were, in order to develop a gender-balanced European Frame of Reference for both beneficiaries [28]. Senperforto applied a community based participatory research methodology, mobilizing stakeholders - AS and refugees, asylum reception professionals, policy makers, civil society $(. .$.$) - from the participating countries in the$ community advisory boards. Further, community researchers - professionals and/or residents that showed good social and communication skills - were trained (standardized training course) to conduct semi-structured interviews. Finally, a KAP survey was conducted.

For a detailed description of Senperforto project and methodology we refer to the article Sexual and Genderbased violence in the European asylum and reception sector: a perpetuum mobile [14].

\section{Participants, sample and data collection}

The Senperforto Project participant sample included 600 residents and professionals living and working in EARF. Residents refer to refugees, AS, and undocumented migrants. Professionals refer to services and health care providers working in the facilities. The inclusion criteria for the residents $(n=398)$ implied being member of the most numerous groups of asylum seeking and unaccompanied minor communities in the host country of research. They had to be staying at, or just having left, an asylum reception facility in the country of research. For professionals $(n=202)$, they had to work, or just stopped working at asylum reception facilities. Regarding the selection of facilities (open or closed (detention) facilities, reception or return centres, private accommodation, urban/rural, unaccompanied minors facilities, AS centres and refugee centres) all official reception facilities were listed; and facilities were selected in order to have at least one category of facility represented among the 
respondents. If more than one centre was available for a certain type of facility, centres were chosen randomly.

Also, a geographical distribution over the country of research was conducted and taken into account to the feasibility of the study. Considering that the situation of the asylum reception sector in each partner country differs, the sampling strategy was adapted to the local situation. In all countries random sampling was used except for Spain and the Netherlands where convenient sampling was applied due to political constraints [14].

.Data was obtained through semi-structured interviews that were conducted by well-trained community researchers. The questionnaire included data on sociodemographic characteristics of the participants and continued with three dimensions of research [1]: knowledge of the respondent on types of SGBV, on occurrence of violence and existence of prevention measures [2]; attitudes regarding SGBV and its prevention within EARF [3]; and a part on their evaluation of effectiveness of existing SGBV prevention and response measures and suggestions. Our study focuses on the first part of the questionnaire, which consisted of 82 closed questions coded with a Likert scale (I fully agree, I agree, Neutral, I do not agree, I fully disagree). Questions described the different acts of SGBV as put forward in the UNHCR guidelines on SGBV prevention and response [1] and inquired on a gender conceptualization, i.e. did they perceive the described behaviour as a violent act when it was done to girls and women, and subsequently if the same act happened to boys and men? Finally, the questionnaire was translated and back translated into the languages of the main groups of AS in the 8 participating countries, as well as the official language of each participating country (Arabic, Dari, Dutch, English, French, Greek, Hungarian, Portuguese, Romanes, Somali, Spanish, Russian, Maltese, Amharic and Tigrigna). A pilot test was done with members of the community advisory board. Prior to the interview respondents had agreed with the community researcher on the chosen language and sex of the interviewer. The interviews were conducted one-to-one at a private place in or near the asylum reception facility.

The Senperforto project applied the ethical and safety guidelines in researching violence recommended by WHO and UNHCR. Furthermore, it complied with the local ethical requirements and received ethical approval from Ghent University Hospital Ethical Committee [B67020096667].

\section{Statistical methods}

The questionnaires from Senperforto project included quantitative and qualitative data. For qualitative data, a framework analysis technique was used, further categorization and introduction into IBM ${ }^{\circ}$ SPSS software. Quantitative data was introduced directly in $\mathrm{IBM}^{\circ}$ SPSS software database. For our study we used a factor analysis approach using
Principal Component Analysis (PCA) [29] for a factor extraction and Varimax rotation, to reduce the volume of the data. We conducted a multivariate analysis of 82 variables regarding SGBV knowledge. PCA analyses data representing observations described by dependent but inter-correlated variables. The goal is to extract the most important information from the original data and to convert this new information as a set of new variables, i.e. principal components (PC) [29]. These PC's were analyzed and named dimensions of SGBV, according to the questions with higher loading result from PCA output. The next step consisted of the recodification of the PC's - dimensions of SGBV - into nominal variables, each of them with three categories (negative, neutral and positive) according to the crosscut values for lower and upper barrier outliers. The lower fence outliers matched with the group of people that fully agreed with the dimension of violence in analysis while the upper fence outliers matched with the ones that fully disagreed.

Subsequently, we selected specific socio-demographic characteristics for residents and professionals. Commonly analyzed socio-demographic characteristics included: country of research (from here called host country), sex, age, marital status, religion, status according to immigration law and type of facility living/working (detention center, open reception center, local reception initiative, return center). Specifically for residents, we included the variables: having children, year of arrival to Europe and to hosting country, kind of accommodation (house, apartment, container, room, homeless...), attained education, daily activity in the country of origin and hosting country. For professionals we included: number of languages speaking and number of languages actually needed at work (here interpreted as language skills), to be working in a reception center by the time of questionnaires and the current occupation. Statistical tests were applied as the Chi-square Test and Fisher's exact test, to understand if significant statistical association exist at the 5\% significance level.

\section{Results \\ Profile of respondents}

The majority of residents were male (64.6\%), aged 19-29 years old (41.4\%) and single (66.8\%); for professionals the majority were women (56.2\%), aged 30-39 years old (42.3\%) and married (56.8\%). For residents, we had 53 different countries of origin, the more representatives were Somalia (20.9\%), Afghanistan (11.1\%), Nigeria (8.5\%), Guinea Conakry (6.3\%) and Iraq (4.5\%). Regarding educational level, $48.5 \%$ of residents had the secondary level of education, $25.6 \%$ had primary education, $14.1 \%$ university degree and $10.8 \%$ no education. For professionals occupational background $50.0 \%$ were social assistants, $21.0 \%$ security or administration related, $19.8 \%$ directors $(20 \%)$, and 
9.0\% health related professionals. Table 1 presents an overview of socio-demographic characteristics for both groups.

\section{SGBV conceptualization \\ Residents}

When analyzing the results of the multivariate analysis of principal components, we found 14 new variables, representing $83.56 \%$ of the total variance of the data. These new variables were analyzed according to the questions with higher PCA output loading, labeled as dimensions of SGBV according to UNHCR definition [1] and represents residents SGBV conceptualization. The questions that correspond to each dimension are described in Table 2.

\section{Professionals}

The multivariate analyze for the group of professionals resulted in 17 new variables representing $86.92 \%$ of the total variance of collected data. These new variables were analyzed and labelled dimensions of SGBV [1] representing professionals SGBV conceptualization. The representative questions of each dimension of SGBV are described in Table 3.

Table 4 shows the conceptualization of SGBV for residents and professionals from EARF grouped according to UNHCR SGBV definition [1].

The association between each dimension of SGBV conceptualization and resident's socio-demographic characteristics or professionals' characteristics are presented in Tables 5 and 6, respectively. Our results describe whether, or not, what is considered a specific behavior/sexual act as violence is different according to sex, age, kind of accommodation (...). We will now describe the significant results first for residents and subsequently for professionals.

\section{Residents}

\section{Sexual violence}

For residents, sexual innuendo conceptualization was associated with the host country $(p=0.010)$, kind of accommodation $(p=0.026)$, the level of education of residents $(p=0.016)$ and daily activity in the host country $(p=0.037)$. This mean that residents living in Belgium and Ireland, in a container, studio or room, with an education (primary, secondary or higher), or do not have a job in the host country tend to disagree that sexual innuendo is a type of SGBV.

Marital rape was associated with the age of residents $(p=0.001)$, and the kind of accommodation where they were living in $(\mathrm{p}=0.001)$. Youth and adults' residents (0-39 years old) or residents living in containers, room or studio tend to disagree that marital rape is a form of violence. Abuse, rape and trafficking was associated with
Table 1 Socio-demographic characteristics of residents and professionals

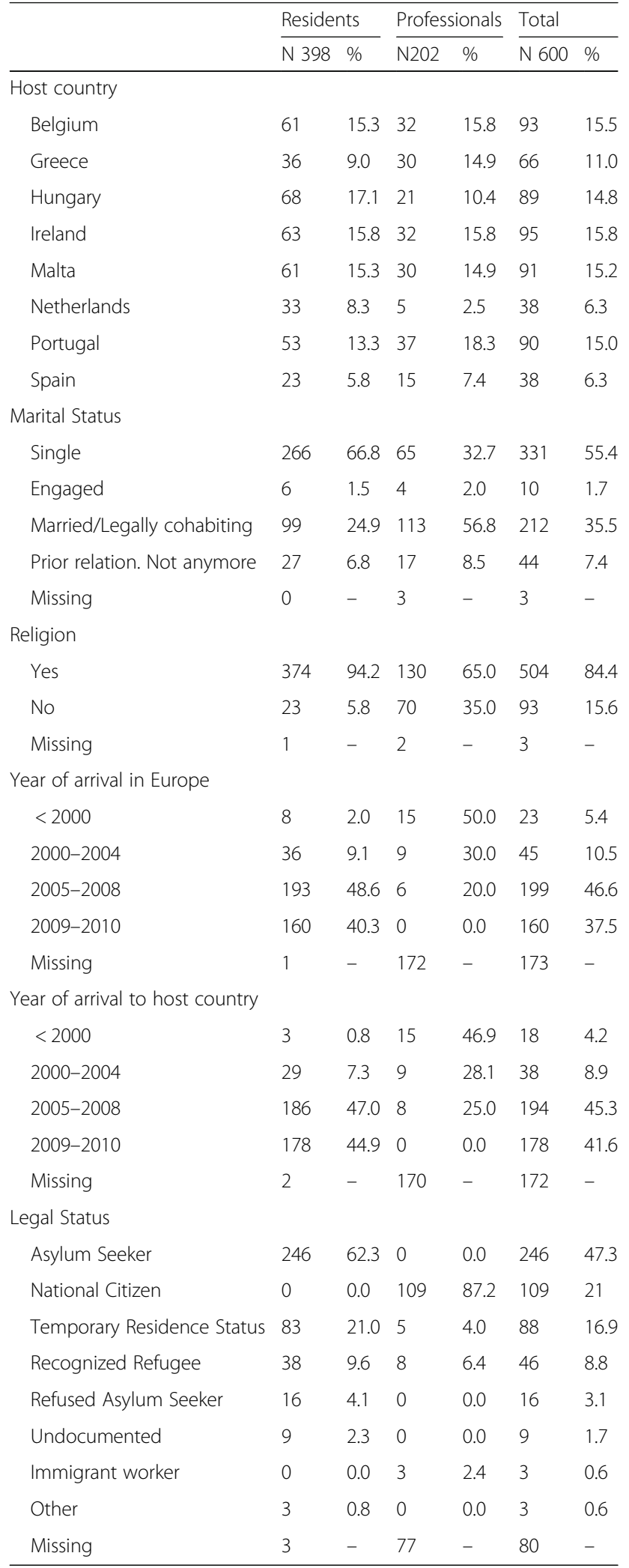


Table 2 Principal component analysis for residents: representative questions and output loading (Varimax variation)

\begin{tabular}{ll}
\hline Residents & \\
\hline SEXUAL VIOLENCE & PCA Loading
\end{tabular}

\begin{tabular}{ll}
\hline PC12 - Sexual innuendo & output \\
Unwelcome and unwanted sexual comments or & 0.862 \\
invitations to girls/women. & \\
And if this happens to boys/men? & 0.876
\end{tabular}

PC4 - Visual sexual Harassment

Made to watch photos of naked persons as a girl/ woman?

And if this happens to boys/men?

Made to watch porn as a girl/woman?

And if this happens to boys/men?

0.802

0.767

PC9 - Marital Rape

Unwanted sex within a relationship and/or marriage $\quad 0.754$ to a girl/woman?

And if this happens to boys/men?

PC1 - Abuse, rape and trafficking

Unwelcome penetration of the vagina and/or anus by an organ or by an object of girl/woman.

And if this happens to boys/men?

Forced prostitution of girls/women?

And if this happens to boys/men?

Sexual slavery/trafficking of girls/women?

And if this happens to boys/men?

Rape of girls/women as a weapon of war?

0.791

And if this happens to boys/men?

0.789

PSYCHOLOGICAL VIOLENCE

PC3 - Humiliation

Unwelcome remarks and comments from nonsexual nature to girls/women.

And if this happens to boys/men?

Teasing, showing no respect, racist or discriminating comments to a girl/woman?

And if this happens to boys/men?

PC6 - Confinement

Someone denying a girl/woman to be together with their partner in private?

And if this happens to boys/men?

HARMFUL CULTURAL PRACTICES

PC10 - Denial of education of girls and women

Neglecting female children, denial from education 0.623 to female children?

And if this happens to boys/men?

PC14 - Genital mutilation

Circumcision of girl/woman?
Table 2 Principal component analysis for residents: representative questions and output loading (Varimax variation) (Continued)

\begin{tabular}{|c|c|}
\hline \multicolumn{2}{|l|}{ Residents } \\
\hline SEXUAL VIOLENCE & $\begin{array}{l}\text { PCA Loading } \\
\text { output }\end{array}$ \\
\hline \multicolumn{2}{|l|}{ PC11 - Early marriage } \\
\hline Child marriage of a girl/woman? & 0.803 \\
\hline And if this happens to boys/men? & 0.817 \\
\hline \multicolumn{2}{|l|}{ PC5 - Honor killing and Maiming } \\
\hline Killing a girl/woman in the name of family honor? & 0.751 \\
\hline And if this happens to boys/men? & 0.745 \\
\hline \multicolumn{2}{|l|}{ SOCIO-ECONOMIC VIOLENCE } \\
\hline \multicolumn{2}{|l|}{ PC13 - Discrimination } \\
\hline $\begin{array}{l}\text { Being treated differently by other people because } \\
\text { of being a girl/woman? }\end{array}$ & 0.569 \\
\hline And if this happens to boys/men? & 0.603 \\
\hline \multicolumn{2}{|l|}{ PC2 - Denial of opportunities and services } \\
\hline $\begin{array}{l}\text { Denial of access to education, health assistance or } \\
\text { remunerated employment because of the } \\
\text { residence status of a girl/woman. }\end{array}$ & 0.792 \\
\hline And if this happens to boys/men? & 0.790 \\
\hline $\begin{array}{l}\text { Denial of access to education, health assistance or } \\
\text { remunerated employment because of being a } \\
\text { girl/woman. }\end{array}$ & 0.774 \\
\hline And if this happens to boys/men? & 0.763 \\
\hline \multicolumn{2}{|c|}{ PC8 - Denial of access to exercise civil, social, economic rights } \\
\hline $\begin{array}{l}\text { As a girl/woman to be isolated, confined and/or } \\
\text { deprived of liberty of movement }\end{array}$ & 0.644 \\
\hline And if this happens to boys/men? & 0.637 \\
\hline \multicolumn{2}{|c|}{ PC7 - Social exclusion/ostracism based on sexual orientation } \\
\hline $\begin{array}{l}\text { Being treated differently by other people because } \\
\text { of the sexual orientation of girl/woman. }\end{array}$ & 0.853 \\
\hline And if this happens to boys/men? & 0.855 \\
\hline
\end{tabular}

host country $(\mathrm{p}=0.001)$. Residents that tend to disagree were hosted in Portugal and Spain.

\section{Psychological violence}

The concept of confinement was significantly associated with age $(p=0.032)$, meaning that residents aged until 18 years old tend to disagree with confinement as a form of violence.

\section{Harmful cultural practices}

Denial of education for girls was associated with marital status $(p=0.033)$ and the fact of having (or not) a religion $(p=0.019)$. Single residents tend to fully agree with this as a form of violence. The conceptualization of genital mutilation as a form of violence was associated with attained education $(\mathrm{p}=0.033)$. 
Table 3 Principal component analysis for professionals: representative questions and output loading (Varimax variation)

\begin{tabular}{ll}
\hline Professionals & \\
\hline SEXUAL VIOLENCE & $\begin{array}{l}\text { PCA Loading } \\
\text { output }\end{array}$
\end{tabular}

PC15 - Sexual innuendo

Unwelcome and unwanted sexual comments or invitations to girls/women

And if this happens to boys/men?

PC3 - Visual sexual harassment

Made to watch somebody undress as a girl/woman? 0.858

And if this happens to boys/men?

Made to watch photos of naked persons as a girl/ woman?

And if this happens to boys/men?

PC14 - Denudement

Having to undress in front of other people watching 0.698 as a girl/woman?

And if this happens to boys/men?

PC1 -Abuse, Rape and Trafficking

Unwelcome penetration of the vagina and/or anus by an organ or by an object of girls/women?

And if this happens to boys/men?

Trafficking of people for their organs?

And if this happens to boys/men?

PC10 - Sexual exploitation

Sex with a girl/woman in exchange for survival, food 0.916 for the children, shelter, money, papers, other favors.

And if this happens to boys/men?

PHYSICAL VIOLENCE

PC8 - Physical assault without permanent consequences

Physical assault with no permanent consequences 0.773 (e.g. hitting, kicking, pulling)

And if this happens to boys/men?

PC5 - Physical assault with permanent consequences

Physical assault with permanent consequences

(e.g. burning, stabbing, maiming)

And if this happens to boys/men?

Killing a girl/woman in the name of family honor?

0.798

And if this happens to boys/men?

0.843

PSYCHOLOGICAL VIOLENCE

PC 12 - Threat and humiliation

Threatening of girls/women with unwelcome not 0.548 sexual acts (make you feel scared....)

And if this happens to boys/men?

Teasing, showing no respect, racist or

discriminating comments to a girl/woman?

And if this happens to boys/men?

PC9 - Verbal violence

Unwelcome remarks and comments from
Table 3 Principal component analysis for professionals: representative questions and output loading (Varimax variation) (Continued)

\begin{tabular}{ll}
\hline Professionals & \\
\hline SEXUAL VIOLENCE & PCA Loading \\
output
\end{tabular}

nonsexual nature to girls/women.

And if this happens to boys/men?

PC13 - Confinement, individual level

As a girl/woman to be isolated, confined and/or deprived of liberty of movement

And if this happens to boys/men?

PC6 - Relational violence

Someone denying a girl/woman to be together with his or her partner in private?

And if this happens to boys/men?

Someone denying a girl/woman to be together with her parents or children in private.

And if this happens to boys/men?

PC16 - Parental relational violence

Someone denying a girl/woman to fulfill her role as a mother (no money for food)

And if this happens to boys/men?

RMFUL CULTURAL PRACTICES

PC17 - Genital mutilation

Circumcision of girl/woman?

And if this happens to boys/men?

PC7 - Early marriage

Child marriage of a girl/woman?

And if this happens to boys/men?

0.862

PC 11 - Honor killing and maiming

Injuring a girl/woman in the name of family honor?

And if this happens to boys/men?

\section{SOCIO-ECONOMIC VIOLENCE}

PC2 - Denial of opportunities and services

Denial of access to education, health assistance or 0.874 remunerated employment because of the ethnic background of a girl/woman

And if this happens to boys/men?

Denial of access to education, health assistance or 0.846 remunerated employment because of the residence status of a girl/woman.

And if this happens to boys/men?

PC4 - Social exclusion/ostracism

Being treated differently by other people because 0.794 of the sexual orientation of a girl/woman?

And if this happens to boys/men?

Being treated differently by other people because of the ethnic background of a girl/woman?

And if this happens to boys/men?

0.780 
Table 4 Residents and professionals - SGBV conceptualization, grouped according to UNHCR SGBV definition

\begin{aligned} \hline Residents & \multicolumn{1}{c}{ Professionals } \\ Sexual Violence & \\ Sexual innuendo & Sexual innuendo \\ Visual sexual harassment & Visual sexual harassment \\ - & Denudement \\ Marital rape & -\end{aligned}

Honor killing and maiming conceptualization was associated with the country of research $(p=0.001)$, sex (male or female) $(p=0.004)$ and age $(p=0.042)$ of residents. Residents hosted in Belgium and Greece, male or aged from 19 to 39 years old tend to disagree with this concept as a form of violence.

\section{Socio-economic violence}

The concept of social exclusion based on sexual orientation was associated with the time of arrival to Europe or hosting country ( $p=0.018$ and 0.007$)$, and daily activity in the country of origin $(p=0.046)$. Residents that arrived recently to the host country or Europe (less than 5 years) or used to have a job in the country of origin tends to fully disagree that social exclusion based on sexual orientation is a form of violence.

\section{Professionals \\ Sexual violence}

For professionals, sexual innuendo was associated with language skills $(p=0.012)$. Professionals with good language skills (at least $2 \mathrm{EU}$ languages) tend to fully disagree. Visual sexual harassment conceptualization was associated with language skills $(p=0.038)$ and status immigration law $(p=0.037)$. The tendency to disagree was found in professionals without the national citizenship and basic language skills (1 EU language). Denudement was associated with the hosting country and language skills $(p=$ $0.030, p=0.000$, respectively). Professionals from Portugal or with basic language skills (1 EU language) tend to fully disagree. Abuse, rape and trafficking conceptualization was different according to the age of professionals $(p=$ 0.021 ). Older professionals ( $>$ then 40 years old) tend to fully disagree. Further, sexual exploitation as a form of violence was associated with hosting country, marital status and language skills $(p=0.002, p=0.014$ and $p=0.031)$. Tendency to fully disagree were found in professionals from Malta, Netherlands and Portugal, married or with good language skills (1 EU and 1 non-EU language).

\section{Physical violence}

The concept of physical assault without permanent consequences as form of violence was significantly associated with hosting country $(p=0.015)$. Professionals working in Hungary tend to fully disagree.

\section{Psychological violence}

Verbal violence was associated with marital status $(p=$ 0.042 ), with single professionals disagreeing more than the average of respondents. Confinement (individual level) as a form of violence was associated with host country $(p=0.004)$, status of immigration $(p=0.001)$, language skills $(p=0.040)$ and the fact of being working $(p=0.005)$. Professionals that have a tendency to fully disagree were from Belgium and the Netherland, without the national citizenship, with good language skills (2 EU languages) or with a current job at the time of the questionnaire.

\section{Harmful cultural practices}

Genital mutilation was associated with professionals' sex $(p=0.043)$, meaning that male professionals tend to fully disagree with it as an act of violence. Early marriage as form of violence was different according to the hosting country, type of reception facility, language skills or the fact of being working ( $p=0.001, p=0.027, p=0.047$ and $p=0.031$ ). Professionals working in Belgium, in open 
Table 5 Residents - SGBV conceptualization and socio-demographic characteristics ( $p$-values: Chi-square Test and Fisher's exact test)

\begin{tabular}{|c|c|c|c|c|c|c|c|c|c|c|c|c|c|c|}
\hline \multirow{3}{*}{$\begin{array}{l}\text { Socio-demographic } \\
\text { characteristics of Residents }\end{array}$} & \multicolumn{14}{|c|}{ Dimensions of SGBV Concept } \\
\hline & \multicolumn{4}{|l|}{ Sexual } & \multicolumn{2}{|c|}{ Psychological } & \multicolumn{4}{|c|}{ Harmful Cultural Practices } & \multicolumn{4}{|c|}{ Socio-economic } \\
\hline & PC 12 & PC 4 & PC 9 & PC 1 & PC 3 & PC 6 & PC 10 & PC 14 & PC 11 & PC 5 & PC 13 & PC 2 & PC 8 & PC 7 \\
\hline lost country & .010 & 0.167 & 0.127 & 0.001 & 0.266 & 0.183 & 0.155 & 0.571 & 0.482 & 0.001 & 0.678 & 0.842 & 0.078 & 0.086 \\
\hline$x$ & 68 & 0.650 & 0.580 & 0.056 & 0.829 & 1.000 & 36 & 0.897 & 0.070 & 0.004 & 0.374 & 1.000 & 0.852 & 0.305 \\
\hline ge & 185 & 0.625 & 0.001 & 0.212 & 0.806 & 0.032 & 0.059 & 0.545 & 0.470 & 0.042 & 0.616 & 1.000 & 0.105 & 0.17 \\
\hline arit & 42 & 0.273 & 0.754 & 0.28 & 0.362 & 0.204 & 3 & 0.363 & 0.189 & 0.5 & 0.253 & 0.565 & 0.911 & 0.716 \\
\hline aving Children & 0.104 & 1.000 & 0.243 & 0.288 & 0.289 & 0.125 & 0.502 & 0.530 & 0.295 & 0.874 & 0.498 & 1.000 & 1.000 & 0.80 \\
\hline |igion & 000 & 1.000 & 1.000 & 0.34 & 0.344 & 0.065 & 0.019 & 0.520 & 0.425 & 0.489 & 0.489 & 1.000 & 1.000 & 0.2 \\
\hline atus immigration Law & 0.195 & 0.087 & 1.000 & 0.321 & 0.626 & 0.798 & 1.000 & 0.124 & 0.328 & 1.000 & 0.161 & 1.000 & 0.458 & 0.064 \\
\hline ar of arrival Europe & 8 & 1.000 & 0.544 & 0.281 & 1.000 & 0 & 79 & 0 & 0.603 & 0.6 & 0 & 1.000 & 0 & n \\
\hline ear of arrival to host country & 0.458 & 1.000 & 0.513 & 0.075 & 1.000 & 0.737 & 0.618 & 0.420 & 0.543 & 1.000 & 0.295 & 1.000 & 0.280 & 0.00 \\
\hline pe of reception facility living & 0.394 & 0.646 & 0.792 & 0.062 & 1.000 & 0.332 & 1.000 & 1.000 & 1.0 & 0.4 & 0. & 1.000 & 1.000 & 1.0 \\
\hline Kind of accommodation & 0.026 & 0.439 & 0.001 & 0.388 & 0.934 & 0.056 & 0.951 & 0.520 & 1.000 & 0.123 & 0.728 & 0.645 & 0.207 & 0.603 \\
\hline tained education & 016 & 0.668 & 0.647 & 0.415 & 0.899 & 0.560 & 0.447 & 0.033 & 0.558 & 0.180 & 0.074 & 0.611 & 0.940 & 0.39 \\
\hline Daily activity country of origin & 0.587 & 0.215 & 1.000 & 0.232 & 0.065 & 1.000 & 0.453 & 0.902 & 0.308 & 0.412 & 0.288 & 1.000 & 0.659 & 0.04 \\
\hline Daily activity host country & 0.037 & 1.000 & 0.233 & 0.412 & 0.502 & 0.650 & 0.834 & 0.467 & 0.176 & 0.278 & 0.758 & 0.308 & 0.070 & 0.744 \\
\hline
\end{tabular}

Significant $\mathrm{p}$-value $p<0.05$ bolded

PC 12: Sexual innuendo; PC 4: Visual sexual harassment; PC 9: Marital rape; PC 1: Abuse, rape and trafficking; PC 3: Humiliation; PC 6: Confinement; PC 10: Denial of education of girls and women; PC 14: Genital mutilation; PC 11: Early marriage; PC 5: Honor killing and maiming; PC 13: Discrimination; PC 2: Denial of opportunities and services; PC 8: Denial of access to exercise civil, social and economic rights; PC 7: Social exclusion/ostracism based on sexual orientation

Table 6 Professionals - SGBV conceptualization and socio-demographic characteristics ( $p$-values: Chi-square Test and Fisher's exact test)

\begin{tabular}{|c|c|c|c|c|c|c|c|c|c|c|c|c|c|c|c|c|c|}
\hline \multirow{3}{*}{$\begin{array}{l}\text { Socio-demographic } \\
\text { characteristics }\end{array}$} & \multicolumn{17}{|c|}{ Dimensions of SGBV Concept } \\
\hline & \multicolumn{5}{|c|}{ Sexual violence } & \multicolumn{2}{|c|}{$\begin{array}{l}\text { Physical } \\
\text { Violence }\end{array}$} & \multicolumn{5}{|c|}{ Psychological violence } & \multicolumn{3}{|c|}{$\begin{array}{l}\text { Harmful Cultural } \\
\text { Practices }\end{array}$} & \multicolumn{2}{|c|}{$\begin{array}{l}\text { Socio- } \\
\text { economic }\end{array}$} \\
\hline & PC 15 & PC 3 & PC 14 & PC 1 & PC 10 & PC 8 & PC 5 & $\begin{array}{l}\mathrm{PC} \\
12\end{array}$ & PC 9 & PC 13 & PC 6 & $\begin{array}{l}P C \\
16\end{array}$ & PC 17 & PC 7 & $\begin{array}{l}P C \\
11\end{array}$ & PC 2 & PC 4 \\
\hline Host country & 0.363 & 0.142 & 0.030 & 0.516 & 0.002 & 0.015 & 0.687 & 0.388 & 0.180 & 0.004 & 0.391 & 0.556 & 0.594 & 0.001 & 0.725 & 0.081 & 0.473 \\
\hline Sex & 0.451 & 0.072 & 0.736 & 0.078 & 0.360 & 0.256 & 0.503 & 0.509 & 0.333 & 0.932 & 1.000 & 0.502 & 0.043 & 0.884 & 0.345 & 0.049 & 0.498 \\
\hline Age & 0.618 & 1.000 & 0.106 & 0.021 & 0.647 & 0.443 & 0.937 & 0.126 & 0.068 & 0.801 & 1.000 & 0.488 & 0.618 & 0.871 & 1.000 & 0.441 & 0.483 \\
\hline Marital status & 0.753 & 0.133 & 0.734 & 0.451 & 0.014 & 0.469 & 0.512 & 0.381 & 0.042 & 0.053 & 0.533 & 0.773 & 0.609 & 0.189 & 0.489 & 0.616 & 0.500 \\
\hline Religion & 0.328 & 1.000 & 0.847 & 0.072 & 0.862 & 0.588 & 0.247 & 0.822 & 0.210 & 1.000 & 0.609 & 1.000 & 0.135 & 0.213 & 0.816 & 0.456 & 0.498 \\
\hline $\begin{array}{l}\text { Status immigration } \\
\text { Law }\end{array}$ & 0.146 & 0.037 & 0.680 & 0.125 & 0.784 & 0.440 & 1.000 & 0.234 & 0.450 & 0.001 & 1.000 & 0.433 & 0.851 & 0.607 & 0.783 & 0.639 & 0.301 \\
\hline $\begin{array}{l}\text { Type of reception } \\
\text { Center working }\end{array}$ & 0.851 & 0.551 & 0.397 & 0.497 & 0.073 & 0.487 & 0.829 & 0.189 & 0.833 & 0.282 & 0.630 & 0.763 & 0.734 & 0.027 & 0.373 & 0.229 & 0.300 \\
\hline $\begin{array}{l}\text { Number of languages } \\
\text { speaking }\end{array}$ & 0.624 & 0.617 & 0.381 & 0.969 & 0.782 & 0.267 & 0.541 & 0.651 & 0.587 & 0.660 & 0.185 & 0.233 & 0.197 & 0.308 & 0.997 & 0.440 & 1.000 \\
\hline $\begin{array}{l}\text { Number of languages } \\
\text { needed at work }\end{array}$ & 0.012 & 0.038 & 0.000 & 0.131 & 0.031 & 0.377 & 0.470 & 0.434 & 0.387 & 0.040 & 0.078 & 0.970 & 0.706 & 0.047 & 0.454 & 0.615 & 0.519 \\
\hline $\begin{array}{l}\text { Actually working in a } \\
\text { Reception center }\end{array}$ & 0.192 & 1.000 & 0.125 & 0.425 & 0.817 & 0.649 & 0.762 & 0.064 & 1.000 & 0.005 & 1.000 & 0.674 & 0.192 & 0.031 & 0.443 & 0.568 & 0.685 \\
\hline Current occupation & 0.720 & 0.593 & 0.063 & 0.696 & 0.213 & 0.193 & 0.747 & 0.235 & 0.079 & 0.460 & 0.833 & 0.469 & 0.836 & 0.353 & 0.528 & 0.930 & 0.819 \\
\hline
\end{tabular}

\section{Significant $\mathrm{p}$-value $\mathrm{p}<0.05$ bolded}

PC 15: Sexual innuendo; PC 3: Visual sexual harassment; PC 14: Denudement; PC 1: abuse, rape and trafficking; PC 10: Sexual exploitation; PC 8: Physical assault without permanent consequences; PC 5: Physical assault with permanent consequences; PC 12: Threat and humiliation; PC 9: Verbal violence; PC 13: Confinement, individual level; PC 6: Relational violence; PC 16: Parental relational violence; PC 17: Genital mutilation; PC 7: Early marriage; PC 11: Honor killing and maiming; PC 2: Denial of opportunities and services; PC 4: Social exclusion and ostracism 
reception facilities or with good language skills tend to fully disagree.

\section{Socio-economic violence}

Denial of opportunities and services as a form of SGBV was associated with sex $(p=0.049)$ and female professionals tend to fully disagree that it represents a form of violence.

In sum, our results suggest that professionals from EARF considered more behaviors as violence than residents.

\section{Discussion}

The scientific understanding of violence and more specifically SGBV is primordial [6] to enhance primary preventive measures. In this sense, if we want to prevent violence in the EARF, understanding the knowledge that residents and professionals have regarding SGBV conceptualization is needed. Our study explored SGBV conceptualization according to residents and professionals from EARF, covering a myriad of countries of origin of the refugees, AS and migrants. Our results show a disparity between what is, or what is not considered a violent behavior. Professionals have shown to have a wider knowledge then residents, considering more acts as violence. We believe this can be related to residents - refugees, AS and undocumented migrants - being described as more vulnerable to SGBV and professionals assuming a privileged position and control towards residents [24].

Conceptualization is a process of development and clarification of concepts; it shapes the field in which a concept is understood, measured and evaluated [30]. Different SGBV conceptualization can be found in the literature. Walby [8] refers that different definitions are used for assault and for rape, which are inconsistent and out of alignment with international law. Also, different SGBV conceptualizations were found in our results for residents and professionals. To consider that definitions of violence have evolved through multiple variations according to the field and the range of forms of violence [30]. A consistent and coherent measurement of violence against women and men will benefit accuracy while measuring changes in society and effectiveness of public services [8]. Given this, we believe a common SGBV conceptualization should be considered while addressing preventive measures. The requisite for developing information, education and communication (IEC) interventions addressing SGBV has already been acknowledged by UNHCR (2003). We believe our results call for the urgent need for IEC interventions, addressing what is, or what is not an SGBV act.

For both groups differences in SGBV conceptualization were found based on specific socio-demographic characteristics. As for gender, our results evoke no differences in SGBV conceptualization. Moreover, the fact that a violent act is directed to a girl/woman or a boy/man is equally considered violence, even though the majority of victims continue to be women [13] However, moving from SGBV conceptualization to specific types of SGBV differences arise. When conducting association tests between types of SGBV and the gender of our respondents we found significant associations. A more in-depth analysis suggests male residents tend to disagree that honor killing and maiming is an SGBV act when compared with the mean average of our respondents. Moreover, male professionals disagree with genital mutilation as a form of SGBV, and female professionals tend to disagree with the denial of opportunities as a form of SGBV.

Another relevant association was found between age and specific forms of SGBV. Results from our study, found that professionals aged above 40 tended to disagree that "abuse, rape and trafficking" is a form of SGBV. This association is particularly screaming for action, once we assist to professionals working with persons, already in a vulnerable situation, and assuming that a behavior legally punishable by law is acceptable. Considering that professionals play an important role in SGBV prevention, and the fact that they are in a privileged position to mitigate SGBV, we believe that our results are screaming for action. From one side we assist to professionals having a broader SGBV conceptualization when compared with residents. However, professionals aged above 40, do not consider abuse, rape and trafficking as a form of SGBV. In this sense, we believe there is a need for a strict screening when engaging professionals to work in EARF and continuous sensitization and training on SGBV. Our results are aligned with previous evidence reporting the requirement for healthcare workers' regular training [25], integrated and widespread preventive and response measures [14]. Furthermore, professionals and persons in power working with migrants and refugees have been identified as potential perpetrators of SGBV [12, 24, 25]. In EARF context, professionals have been identified as potential perpetrators of SGBV, especially socio-economic violence [14].

Specific types of SGBV not being recognized as a violent act is of major importance while addressing preventive measures in asylum centers. Residents and professionals must have a complete and equal knowledge regarding all types of SGBV to avoid being victims and/or aggressors. Placing SGBV in a public health perspective, we can assume SGBV conceptualization is the baseline for primary prevention [5]. Furthermore, significant association with socio-demographic characteristics have arisen from our results. This fact shows the importance of recognizing the intersectionality of SGBV concepts $[8,27]$ with characteristics, such as gender, age, social status. We call for an urgent action from all stakeholders to increase the knowledge on SGBV of residents and professionals, based on IEC interventions, as the baseline to prevent violence before it occurs.

Future pertinent research regards the potential association between SGBV conceptualization and case disclosure. 
Moreover, it is of utmost importance to have a clear and in-depth understanding of professionals' SGBV conceptualization. The fact that professionals might perpetuate SGBV acts, and exercise a higher power relation towards residents, represents a call for intervention. We challenge researchers to go beyond the understanding of professionals' SGBV conceptualization and to consider the influence of it with the potential perpetuation of violence. Another relevant aspect to consider in the future regards the evaluation of primary preventive measures, and specifically the focus on promoting and implementing a widespread SGBV conceptualization among residents, professionals and host population. If we reach a level where professionals and residents have similar SGBV conceptualization, will we still witness such high levels of SGBV?

Even though relevant findings were described it is important to acknowledge potential limitations. The Senperforto project applied multi-types of sampling methods, as random and representative sampling were not possible in all countries. However, even though our results cannot be generalized, we believe it can be transferable to similar populations in comparable contexts, in a sense that a broad SGBV conceptualization is presented in our research - understanding refugees, AS and undocumented migrants' perspective and also professional's perspective. Specifically related with SGBV conceptualization, we cannot exclude that community researchers conducting the interviews during the implementation of Senperforto project, could have had a different SGBV conceptualization, even with the implementation of a standardized training.

Stepping out of EARF, it would be pertinent to compare SGBV conceptualization between migrants and hosting population, once public health policies should be adapted to the cultural and structural context. Moreover, it is important to consider the challenge of having refugees, AS and undocumented migrants with different SGBV conceptualization "integrated" in European countries, especially if they have a narrow concept. Accordingly, we believe migrants might be exposed to higher vulnerability to both victimization and perpetration. Considering the recent migration wave to European countries, it urges to address this issue. SGBV conceptualization needs to be addressed equally, not only for migrants and professionals, but also for hosting populations. What is or what is not an SGBV act should not differ according to a migration status. By not doing it, we believe European countries and its representatives might be increasing migrants' vulnerability and inducing obstacles to their integration.

\section{Conclusion}

Residents and professionals from European asylum centers have a different concept of what SGBV entails with professionals considering more acts as violence then residents. However, types of SGBV were considered equally violent if afflicted upon female or male. Some acts that were not considered violence by the professionals are legally a crime, increasing the perpetration risk.

The Socio-Ecological Model as an explanatory model of SGBV helps moving from the individual conceptualization of SGBV to a societal conceptualization considering the influences of relational, community and societal factors [31].

SGBV conceptualization is the core to primary prevention of SGBV and it should focus on harmonizing the concept, IEC activities, training and "collegiate" discussion/participatory activities towards consensus and European policies. What is considered (or not) a violent behavior should be taken into consideration if we want to mitigate SGBV.

We call for the development, implementation and monitoring of European-wide SGBV prevention programs in EARC context, aligned with SGBV conceptualization of the target population.

\section{Abbreviations \\ EARF: European asylum reception facilities; SGBV: sexual and gender-based violence; AS: asylum-seeker; UNHCR: United Nations High Commissioner for Refugees; EU: European Union; PCA: principal component analysis; PC: principal component; KAP: knowledge, attitudes and practices; IEC: information, education and communication}

\section{Acknowledgements}

We are grateful to the Academic Network for Sexual and Reproductive Health and Rights Policy -ANSER for having granted us the opportunity to further analyse the Senperforto data cross-nationally "which contributes to the definition of primary preventive measures for SGBV internationally. ANSER promotes sexual and reproductive health research and its translation into policies.

\section{Funding}

The Senperforto project was funded by European Daphne Fund (JLS/2007/ DAP-1/084).

Availability of data and materials

Please contact the author for data requests.

\section{Authors' contributions}

IK designed and coordinated Senperforto project. IK and SD contributed to the sampling and recruitment of respondents, the data gathering and first analysis. CO continued with the in-depth analysis of the data, to which all authors contributed as well as to the design, the writing, and the revision of drafts of this paper. Finally, all the authors have read and agreed on the final paper.

Ethics approval and consent to participate

The Senperforto study protocol applied the WHO and UNHCR ethical and safety guidelines in researching violence, complied with the local ethical requirements and received ethical approval from Ghent University Hospital Ethical Committee [B67020096667].

\section{Consent for publication}

Not applicable.

\section{Competing interests}

The authors declare that they have no competing interests.

\section{Publisher's Note}

Springer Nature remains neutral with regard to jurisdictional claims in published maps and institutional affiliations. 


\section{Author details}

${ }^{1}$ Global Health and Tropical Medicine, GHTM, Instituto de Higiene e Medicina Tropical, IHMT, Universidade NOVA de Lisboa, Rua da Junqueira 100, 1349-008 Lisbon, Portugal. ${ }^{2}$ Centro de Investigação em Saúde Pública, Escola Nacional de Saúde Pública, Universidade NOVA de Lisboa, Lisbon, Portugal. ${ }^{3}$ International Centre for Reproductive Health, Department of Public Health and Primary Care, Faculty of Medicine \& Health Sciences, Ghent University, Ghent, Belgium.

Received: 17 November 2018 Accepted: 7 May 2019

Published online: 31 May 2019

\section{References}

1. UNHCR. Sexual and gender-based violence against refugees, Returnees and internally displaced persons - guidelines for prevention and response. 2003.

2. World Health Organization. World report on violence and health: summary. Geneva: World Health Organisation; 2002.

3. Inter-Agency Standing Committee. Guidelines for integrating gender-based violence interventions in humanitarian action: reducing risk, promoting resilience and aiding recovery; 2015. p. 1-366. Available from: http:// gbvguidelines.org/wp-content/uploads/2015/09/2015-IASC-Gender-basedViolence-Guidelines_lo-res.pdf

4. Lori JR, Boyle JS. Forced migration: health and human rights issues among refugee populations. Nurs Outlook. 2015;63(1):68-76. Available from: https:// doi.org/10.1016/j.outlook.2014.10.008

5. Krug EG, Mercy JA, Dahlberg LL, Zwi AB. The world report on violence and health. Lancet. 2002;360(9339):1083-8 Available from: http://linkinghub. elsevier.com/retrieve/pii/S0140673602111330.

6. de Haan W. Violence as an essentially contested concept. In: Body-Gendrot S, Spierenburg P, editors. Violence in Europe. New York: Springer New York; 2008 p. 27-40. Available from: http://link.springer.com/10.1007/978-0-387-74508-4_3.

7. Keygnaert I, Guieu A. What the eye does not see: a critical interpretive synthesis of European Union policies addressing sexual violence in vulnerable migrants. Reprod Health Matters. 2015;23(46):45-55.

8. Walby S, Towers J, Balderston S, Corradi C, Francis B, Heiskanen M, et al. The concept and measurement of violence sharing economy against women measurement of violence. Bristol: Policy Press; 2017.

9. Salman KF, Resick LK. The description of health among Iraqi refugee women in the United States. J Immigr Minor Heal. 2015;17(4):1199-205 Available from: http://link.springer.com/10.1007/s10903-014-0035-6.

10. Keygnaert I. Sexual violence and sexual health in refugees, asylum seekers and undocumented migrants in Europe and the European Neighbourhood: determinants and desirable prevention. Ghent: Ghent University; Faculty of Medicine and Health Sciences. 2014.

11. Santos-Hövener C, Marcus U, Koschollek C, Oudini H, Wiebe M, Ouedraogo $\mathrm{Ol}$, et al. Determinants of HIV, viral hepatitis and STI prevention needs among African migrants in Germany; a cross-sectional survey on knowledge, attitudes, behaviors and practices. BMC Public Health. 2015; 15(1):753 Available from: http://bmcpublichealth.biomedcentral.com/ articles/10.1186/s12889-015-2098-2.

12. Arsenijević J, Schillberg E, Ponthieu A, Malvisi L, Ahmed WAE, Argenziano S, et al. A crisis of protection and safe passage: violence experienced by migrants/refugees travelling along the Western Balkan corridor to Northern Europe. Confl Health. 2017;11(1):6 Available from: http://conflictandhealth. biomedcentral.com/articles/10.1186/s13031-017-0107-z.

13. Keygnaert I, Vettenburg $\mathrm{N}$, Temmerman $\mathrm{M}$. Hidden violence is silent rape: sexual and gender-based violence in refugees, asylum seekers and undocumented migrants in Belgium and the Netherlands. Cult Health Sex. 2012;14(5):505-20 Available from: https://doi.org/10.1080/13691058. 2012.671961 .

14. Keygnaert I, Dias SF, Degomme O, Deville W, Kennedy P, Kovats A, et al. Sexual and gender-based violence in the European asylum and reception sector: a perpetuum mobile? Eur J Pub Health. 2015;25(1):90-6 Available from: https:/ academic.oup.com/eurpub/article-lookup/doi/10.1093/eurpub/cku066.

15. Bronfenbrenner $U$. The ecology of human development: experiments by nature and design. Cambridge: Harvard University Press; 1979.

16. Blazek M. Migration, vulnerability and the complexity of violence: experiences of documented non-EU migrants in Slovakia. Geoforum. 2014; 56:101-112. Available from: http://www.sciencedirect.com/science/article/ pii/S0016718514001535
17. Boxer P, Rowell Huesmann L, Dubow EF, Landau SF, Gvirsman SD, Shikaki K, et al. Exposure to violence across the social ecosystem and the development of aggression: a test of ecological theory in the IsraeliPalestinian conflict. Child Dev. 2013;84(1):163-77 Available from: http://doi. wiley.com/10.1111/j.1467-8624.2012.01848.x.

18. World Health Organization. Global and regional estimates of violence against women: prevalence and health effects of intimate partner violence and non-partner sexual violence. Geneva: World Health Organization; 2013.

19. Basile KC, DeGue S, Jones K, Freire K, Dills J, Smith SG, et al. STOP SV: a technical package to prevent sexual violence. Atlanta; 2016. Available from: http://www.cdc.gov/violenceprevention/pdf/sv-prevention-technicalpackage.pdf. Accessed 20 sep 2018.

20. Krahé B, Berger A, Vanwesenbeeck I, Bianchi G, Chliaoutakis J, FernándezFuertes AA, et al. Prevalence and correlates of young people's sexual aggression perpetration and victimisation in 10 European countries: a multilevel analysis. Cult Health Sex. 2015;17(6):682-99. Available from: http://www. tandfonline.com/doi/full/. https:/doi.org/10.1080/13691058.2014.989265.

21. Minh A, Matheson F, Daoud N, Hamilton-Wright S, Pedersen C, Borenstein $\mathrm{H}$, et al. Linking childhood and adult criminality: using a life course framework to examine childhood abuse and neglect, substance use and adult partner violence. Int J Environ Res Public Health. 2013;10(11):5470-89 Available from: http://www.mdpi.com/1660-4601/10/11/5470/.

22. Pottie K, Dahal G, Georgiades K, Premji K, Hassan G. Do first generation immigrant adolescents face higher rates of bullying, violence and suicidal Behaviours than do third generation and native born? J Immigr Minor Health. 2015;17:1557-66 Available from: http://link.springer.com/10.1007/ s10903-014-0108-6.

23. Lee BX, Kjaerulf F, Turner S, Cohen L, Donnelly PD, Muggah R, et al. Transforming our world: implementing the 2030 agenda through sustainable development goal indicators. J Public Health Policy. 2016;37(S1): 13-31 Available from: http://link.springer.com/10.1057/s41271-016-0002-7.

24. Keygnaert I, Dialmy A, Manco A, Keygnaert J, Vettenburg N, Roelens K, et al. Sexual violence and sub-Saharan migrants in Morocco: a community-based participatory assessment using respondent driven sampling. Glob Health. 2014; 10:32 Available from: http://www.globalizationandhealth.com/content/10/1/32.

25. van de Ameele S, Keygnaert I, Rachidi A, Roelens K, Temmerman M. The role of the healthcare sector in the prevention of sexual violence against sub- Saharan transmigrants in Morocco : a study of knowledge, attitudes and practices of healthcare workers. BMC Health Serv Res. 2013;13(1):77 Available from: http://www.biomedcentral.com/1472-6963/13/77.

26. World Health Organization. Violence prevention: the evidence. Geneva: World Health Organization; 2010.

27. Walby S, Strid S. Intersectionality: Multiple Inequalities in Social Theory; 2012.

28. Keygnaert I, Vangenechten J, Devillé W, Frans E, Temmerman M. Senperforto Frame of Reference for Prevention of SGBV in the European Reception and Asylum Sector. Ghent: Magelaan cvba; 2010.

29. Abdi H, Williams L. Principal component analysis. Wiley Interdiscip Rev Comput Stat. 2010;2(4):433-59 Available from: http://doi.wiley.com/10. 1002/wics.101.

30. Scriver S, Durvry N, Ashe S, Raghavendra S, O'Donovan D. Conceptualising violence: a holistic approach to understanding violence against women and girls. 2015; Available from: http://www.whatworks.co.za

31. Gilligan J, Lee BX, Garg S, Blay-Tofey M, Luo A. A case for studying country regimes in the public health model of violence. J Public Health Policy. 2016; 37(S1):133-44 Available from: http://ink.springer.com/10.1057/s41271-016-0027-y.

\section{Ready to submit your research? Choose BMC and benefit from:}

- fast, convenient online submission

- thorough peer review by experienced researchers in your field

- rapid publication on acceptance

- support for research data, including large and complex data types

- gold Open Access which fosters wider collaboration and increased citations

- maximum visibility for your research: over $100 \mathrm{M}$ website views per year

At BMC, research is always in progress.

Learn more biomedcentral.com/submissions 